\title{
Entre a formação e a prática: o caso dos vigilantes patrimoniais na saúde
}

\author{
Rachel Aisengart Menezes ${ }^{1}$ \\ Priscila Cassemiro ${ }^{2}$
}

Resumo

As instituições de saúde contam com o trabalho de vigilantes patrimoniais. No contexto destas instituições atuam para além das atividades normatizadas na legislação da categoria. A formação desses profissionais, no entanto, não abrange as especificidades e os desafios enfrentados em sua rotina laboral. Este artigo aborda os nexos entre a formação técnica e o trabalho desses profissionais, com base em pesquisa sobre as leis e normas que regem seu trabalho, e em entrevistas com onze vigilantes patrimoniais que atuam em cinco instituições públicas de saúde do município do Rio de Janeiro. A investigação contou também com análise de notícias veiculadas na internet. Os entrevistados foram selecionados por meio de indicações, o que permitiu ampla apreensão da realidade de seu trabalho em unidades de saúde, em seus diferentes níveis de complexidade. A formação oficial do vigilante patrimonial abrange um curso de formação e cursos obrigatórios de reciclagem a cada dois anos. A pesquisa documental evidenciou que esses cursos oferecem escassa informação sobre a atuação na área da saúde. Em geral, o aprendizado ocorre de maneira informal, a partir da observação do desempenho de colegas, das orientações do supervisor e de profissionais da saúde. A investigação demonstrou que os vigilantes inseridos em unidades de saúde efetuam um número expressivo de tarefas não normatizadas para sua profissão, como triagem informal, transporte de pacientes e contenção de pacientes e familiares, para as quais não receberam informações ou orientação.

Palavras-chave: trabalho; profissional de segurança; vigilante patrimonial; instituição de saúde.

\section{Between training and practice: the case of security personnel in health institutions}

Abstract

Health institutions rely on the work of security personnel. In the context of these institutions they act in addition to the activities regulated in the legislation of the category. The training of these professionals, however, does not cover the specificities and challenges faced in their work routine. This article discusses the links between technical training and the work of these professionals, based on research on the laws and norms that rule their work, and interviews with eleven security workers of five public health institutions in Rio de Janeiro. The investigation also relied on analysis of Internet news. The interviewees were selected through nominations, which allowed a wide apprehension of the reality of their work in health units in its different levels of complexity. The official training of the security personnel covers a training course and compulsory updating courses every two years.

1 Professora do Instituto de Estudos em Saúde Coletiva (IESC) da Universidade Federal do Rio de Janeiro (UFRJ).

2 Mestre em Saúde Coletiva pelo Instituto de Estudos em Saúde Coletiva (IESC) da Universidade Federal do Rio de Janeiro (UFRJ). 
The research has shown these courses offer little information about health work. In general, learning occurs informally, based on observation of peer performance, supervisor and health professional orientation. Research has shown caretakers in health care facilities perform a significant number of non-standardized tasks for their profession, such as informal screening, patient transportation, and patient and family restraint for which they have not received information or guidance.

Keywords: work; security; patrimonial vigilante; health institution.

\section{Introdução}

As instituições de saúde contam com o trabalho de diferentes profissionais de muitas áreas, alguns considerados integrantes da equipe de saúde, e outros não. Dentre esses profissionais não categorizados tradicionalmente como integrantes da equipe de saúde encontramse os vigilantes patrimoniais, atores presentes em todas as instituições de saúde, que por vezes passam despercebidos. Para além do esperado de um "vigilante patrimonial", cujo trabalho seria garantir a incolumidade física das pessoas e a integridade do patrimônio, os vigilantes em unidades de saúde atuam de forma ampla, para além das atividades normatizadas e definidas na legislação que rege a categoria. Em algumas instituições, por exemplo, eles são responsáveis por uma triagem informal de quem busca atendimento de emergência; por auxiliar no transporte de enfermos (maca ou cadeira de rodas) ou, ainda, por recepcionar os pacientes e fornecer informações sobre locais de consulta. Contudo, a formação técnica desses profissionais é realizada por intermédio de um curso obrigatório de dois anos, que pode ser estendida com a frequência a outros cursos, que não abordam as especificidades e os desafios enfrentados em unidades de saúde.

Este artigo baseia-se em uma pesquisa que objetivou apreender narrativas de vigilantes patrimoniais acerca de seu trabalho em unidades de saúde. A seguir são apresentados dados da investigação, a metodologia empregada e, na sequência, a partir das falas dos entrevistados, uma apresentação dos nexos entre a formação e o trabalho desses profissionais.

\section{A investigação}

A pesquisa, desenvolvida a partir de perspectiva teórico-metodológica das Ciências Sociais voltadas ao campo da saúde, contou com metodologia qualitativa e análise de dois tipos de material. O primeiro pode ser subdividido em dois: notícias veiculadas na internet sobre o tema do trabalho de vigilantes patrimoniais em unidades de saúde e consulta às normas e leis que regem o trabalho desta categoria profissional. $\mathrm{O}$ segundo tipo de material consiste no conjunto de entrevistas gravadas, a partir de assinatura de Termo de Consentimento Livre e Esclarecido, com onze vigilantes patrimoniais que atuam em cinco instituições de saúde, desde clínicas de saúde da família a hospitais de atenção terciária. Este formato permitiu ampla apreensão da realidade do trabalho de vigilantes em unidades de saúde, assim como dos desafios por eles enfrentados, nos distintos níveis de complexidade.

A análise documental teve como material a legislação que embasa as atividades dos vigilantes e buscas em bases de dados. O levantamento em bases de dados foi realizado nas bases BVS, Capes e Scielo. Em levantamento bibliográfico inicial sobre o tema não foram encontrados artigos dedicados ao trabalho realizado por vigilantes em unidades de saúde. Entretanto, apesar de os estudos não terem como objeto central o trabalho desses profissionais, há menção às diversas tarefas que realizam em unidades de saúde. $\mathrm{Na}$ internet também foi possível acesso a notícias que expõem a realidade cotidiana laboral dos vigilantes, bem como o posicionamento da categoria profissional, no que concerne às condições de trabalho no Brasil.

Normas e leis que regem a formação e o trabalho do vigilante patrimonial 
Segundo o Ministério do Trabalho e Emprego, na Classificação Brasileira de Ocupações (2002), os "vigilantes e guardas de segurança":

Vigiam dependências e áreas públicas e privadas com a finalidade de prevenir, controlar e combater delitos como porte ilícito de armas e munições e outras irregularidades, zela pela segurança das pessoas, do patrimônio e pelo cumprimento das leis e regulamentos; recepcionam e controlam a movimentação de pessoas em áreas de acesso livre e restrito; fiscalizam pessoas, cargas e patrimônio; vigiam parques e reservas florestais, combatendo inclusive focos de incêndio, vigiam presos. Comunicam-se via rádio ou telefone e prestam informações ao público e aos órgãos competentes (BRASIL, 2002, p. 624).

Os vigilantes patrimoniais atuam em diversos contextos, como bancos, estabelecimentos comerciais, de ensino e, também, em instituições de saúde. A lei no 7.102, de 20 de junho de 1983, regulamenta a profissão, estabelecendo normas para constituição e funcionamento das empresas particulares que exploram serviços de vigilância e, também, as condições para o exercício da profissão de vigilante. Segundo esta lei, esse profissional deve preencher os seguintes requisitos: ser brasileiro; ter idade mínima de 21 anos; ter nível de instrução correspondente à quarta série do primeiro grau; ter sido aprovado em curso de formação de vigilante em estabelecimento com funcionamento autorizado nos termos desta lei; ter sido aprovado em exame de saúde física, mental e psicotécnico; não possuir antecedentes criminais registrados e estar quite com as obrigações eleitorais e militares.

A formação dos vigilantes é regulamentada pela Portaria $\mathrm{n}^{\circ} 3.233$, de 10 de dezembro de 2012, que dispõe sobre as normas relacionadas às atividades de Segurança Privada. Nesta mesma lei, o profissional da vigilância é definido em termos de sua formação:

III - vigilante: profissional capacitado em curso de formação, empregado de empresa especializada ou empresa possuidora de serviço orgânico de segurança, registrado no DPF, e responsável pela execução de atividades de segurança privada (PORTARIA no 3.233/12).

Além disso, a Portaria retoma em vários trechos a obrigação das empresas de contar, em seu quadro de profissionais, apenas com aqueles que concluíram essa formação e, também, aborda a garantia de reciclagem desses profissionais, que deve ocorrer a cada dois anos (PORTARIA n ${ }^{\circ}$ $3.233 / 12$ ). Os cursos previstos por esta Portaria estão explicitados na seção II, Art. 156:

Seção II Dos Cursos de Formação, Extensão e Reciclagem

Art. 156. São cursos de formação, extensão e reciclagem: I - curso de formação de vigilante (Anexo I); II - curso de reciclagem da formação de vigilante (Anexo II); III - curso de extensão em transporte de valores (Anexo III); IV - curso de reciclagem em transporte de valores (Anexo IV); $\mathrm{V}$ - curso de extensão em escolta armada (Anexo V); VI - curso de reciclagem em escolta armada (Anexo VI); VII - curso de extensão em segurança pessoal (Anexo VII); VIII - curso de reciclagem em segurança pessoal (Anexo VIII); IX - curso de extensão em equipamentos não letais I (Anexo IX); $\mathrm{X}$ - curso de extensão em equipamentos não letais II (Anexo X); e XI - curso de extensão em segurança para grandes eventos (ANEXO XI. PORTARIA $n^{\circ}$ $3233 / 12)$.

O Anexo I da Portaria, por sua vez, explicita o programa do curso, apresentando o perfil esperado do vigilante e as informações específicas sobre as diferentes disciplinas do curso.

PERFIL DO VIGILANTE: O vigilante deverá ter o seguinte perfil profissional: a) preventivo/ ostensivo: atributo de o vigilante ser visível ao público em geral, a fim de evitar a ação de delinquentes, manter a integridade patrimonial e dar segurança às pessoas; b) proatividade: ação de antever e se antecipar ao evento danoso, com o fim de evitálo ou de minimizar seus efeitos e, principalmente, visar à adoção de providências para auxiliar os agentes de segurança pública, como na coleta das 
primeiras informações e evidências da ocorrência, de preservação dos vestígios e isolamento do local do crime; c) relações públicas; qualidade de interação com o público, urbanidade, sociabilidade e transmissão de confiança, priorizando o atendimento adequado às pessoas com deficiência; d) vigilância; atributo de movimento, dinamismo e alerta, contrapondo-se ao conceito estático; e) direitos humanos; respeito à dignidade e à diversidade da pessoa humana, compromisso que o Brasil assumiu perante a comunidade internacional e princípio constitucional de prevalência dos direitos humanos; f) técnico-profissional; capacidade de empregar todas as técnicas, doutrinas e ensinamentos adequados para a consecução de sua missão; g) adestramento; atributo relacionado à desenvoltura corporal, com aprimoramento físico, domínio de defesa pessoal e capacitação para o uso proporcional da força através do emprego de tecnologias não letais e do uso da arma de fogo, como último recurso de defesa própria ou de terceiros; h) higidez física e mental; certeza de não ser possuidor de patologia física ou mental; i) psicológico; perfil psicológico adequado ao desempenho do serviço de vigilante; e j) escolaridade; $4^{\mathrm{a}}$ série (exigência legal). (PORTARIA nº 3.233/12).

O trabalho nos hospitais é abordado na disciplina Vigilância, em meio a outros espaços de atividade específica dos vigilantes, como escola, indústria e shopping:

Vigilância

Carga horária: 14 h/a Avaliação: V/F (2 h/a) Objetivo da disciplina: a) desenvolver conhecimentos sobre vigilância geral e sobre as áreas de vigilância especializadas, como banco, shopping, hospital, escola, indústria, com o fim de manter a integridade do patrimônio que guarda, executar os serviços que lhe competem e realizar uma vigilância dinâmica, alerta, integrada e interativa; b) capacitar o aluno a identificar as técnicas de vigilância em geral e compreender as funções do vigilante, bem como avaliar sua importância num esquema de segurança; c) desenvolver conhecimentos sobre o plano de segurança das empresas; dotar o aluno de conhecimentos específicos que o capacitem ao desempenho das atribuições de promover a segurança física de instalações, em sua área de atuação, adotando medidas de prevenção e repressão de ocorrências delituosas; e d) identificar emergência, evento crítico e crise (PORTARIA n ${ }^{\circ}$ $3233 / 12)$.

O curso de formação de vigilantes, curso básico para ingresso nesse mercado, é o único, dentre todos os descritos na portaria, que aborda um conteúdo para preparar os profissionais para a realidade específica de unidades de saúde. No programa deste curso, o período de 14 horas é disponibilizado para apresentação de diversos cenários, inclusive o de unidade de saúde. Assim, o profissional conclui o curso básico com informações breves acerca desta "área de vigilância especializada".

O Manual do Vigilante, escrito pela Associação Brasileira de Cursos de Formação e Aperfeiçoamento de Vigilantes (ABCFAV) em 2007 e homologado pelo Departamento de Polícia Federal, possui um tópico sobre a vigilância em hospitais. De acordo com este manual, os principais delitos ocorridos nesse contexto consistem em furtos de medicamentos, sequestro e troca de recém-nascidos, assassinatos e sequestro de criminosos internados. Apontase a importância de "equilíbrio emocional" do profissional, por se tratar de local "propício ao conflito e desgaste psíquico" (ABCFAV, 2007, p. 109). Aborda-se especificamente a Portaria como local de acesso, o horário da visita como momento crítico e as medidas de segurança a serem acionadas para prevenção e combate aos riscos indicados. Ainda segundo o Manual, são locais considerados críticos para a segurança: o quadro de disjuntores, o sistema de refrigeração, a casa de máquina de elevadores, o reservatório de água, a gasometria, a central de processamento de dados, a central telefônica, o armazenamento e tratamento de resíduos, o heliponto, a central de segurança, a sala de geradores, o berçário, a farmácia, a pediatria, o pronto socorro, a psiquiatria e o centro cirúrgico e/ou obstétrico.

O vigilante empregado neste local de trabalho 
deve estar atento a todos os movimentos internos, em especial nas dependências em que o acesso seja restrito a determinadas pessoas e horários pré-estabelecidos pela Direção. O equilíbrio emocional é de fundamental importância, pois se trata de local onde as pessoas constantemente entram em desespero e, por vezes, demonstrando real insatisfação em relação ao atendimento dos médicos e seus auxiliares, sendo, portanto, propício ao conflito e desgaste psíquico. A portaria é o local de acesso ao público em geral, devendo o vigilante ficar atento às vias de acesso para a parte interna das instalações que são restritas a funcionários e pessoas autorizadas. Outro momento crítico é o horário das visitas, em que a atenção deve ser redobrada, pois os grupos criminosos que praticam delitos em hospitais são estrategistas e na maioria das vezes se passam por enfermeiros, médicos, funcionários de empresas prestadoras de serviços etc. Como em todos os locais de vigilância, a instalação de medidas de segurança é de fundamental importância para prevenir as ações criminosas, como por exemplo: Circuito Fechado de TV, em todos os pontos possíveis, inclusive nos berçários; pulseiras com código de barras pelos pacientes; controle de visitantes através de identificação e biometria (íris, impressões digitais), com o devido registro de dados; câmeras nas farmácias, com monitoramento e acesso controlado eletronicamente através de senhas pessoais, etc. (ABCFAV, 2007, p. 109).

No levantamento realizado nas bases de dados são descritos contextos nos quais os vigilantes atraem o olhar do pesquisador por realizarem tarefas além de seu escopo de atuação, como triagem de pacientes, encaminhamento para lugares de atendimento, entrega de fichas de atendimento, participação em grupos de discussão (GIGLIO-JACQUEMOT, 2005; BARROS et al, 2013; QUEIROZ et al, 2013; COELHO, JORGE, 2009; CALEGARI e LIMA, 2008). Faria (2010) observou que os profissionais da segurança ultrapassavam as funções estritamente relacionadas ao papel de um vigilante do patrimônio físico da instituição, sobretudo no que concerne às interações com os usuários do serviço de saúde. Eles eram os primeiros a ter contato com os usuários, sendo os responsáveis pela abertura dos portões da unidade, organização da fila e distribuição de senhas, juntamente com os profissionais da recepção. Assumiam outras funções para além daquelas esperadas para seu cargo, como carregar pacientes mais fragilizados, conduzir até as salas de atendimento, atender ao telefone, entregar resultados de exames e executar outras funções que extrapolavam o "protocolo" de vigiar.

De forma semelhante, em etnografia empreendida por Giglio-Jacquemot (2005) em um serviço de emergência, esta autora evidencia como o trabalho dos seguranças nessa unidade de saúde é importante na triagem informal dos pacientes e, também, para a manutenção da ordem no ambiente da sala de espera. Apesar de não terem recebido treinamento formal em saúde que os capacitasse a identificar sinais de urgência médica ou de piora clínica, os funcionários de segurança se consideravam em condições de identificar sinais de urgência. Em certas ocasiões, a opinião deste ator social foi fundamental para garantir atendimento imediato a pacientes graves.

Observa-se, portanto, que os desafios enfrentados e o trabalho realizado se distinguem dos desenvolvidos em outras áreas da vigilância patrimonial. A prerrogativa de "curso de formação de vigilante, realizado em estabelecimento com funcionamento autorizado nos termos dessa lei" poderia surgir então como complemento à legislação na normatização da atividade, uma vez que no mercado encontram-se cursos que se pretendem especializados em "vigilância patrimonial hospitalar", e cujo currículo interessaria conhecer, para compreender de que forma há adequação entre aquilo que é normatizado enquanto aprendizado curricular e aquilo que é praticado no cotidiano nos serviços de saúde.

No que tange à formação dos vigilantes, a pesquisa na internet revela a existência de diversas empresas no ramo de cursos básicos e de especializações direcionadas a esses profissionais. Há inclusive cursos que se pretendem especializados em "vigilância patrimonial hospitalar". Diversas empresas promovem esses 
cursos, mas a oferta de dados sobre o trabalho em ambiente hospitalar é limitada. Na busca realizada em fevereiro de 2016, a partir dos termos "formação vigilantes rj", no Google, o resultado contava com referência a várias empresas. A pesquisa em seus sites demonstrou que todas oferecem o curso básico de Formação de Vigilante e os cursos explicitados na Portaria $n^{\circ} 3.233$, além de outros não previstos neste documento. Entretanto, poucas empresas sugerem cursos direcionados à área da vigilância patrimonial hospitalar. Dentre as empresas pesquisadas, a Cactus oferece o curso "Segurança Hospitalar", com quatro horas/aula e apenas uma disciplina, intitulada "Procedimentos em Segurança Hospitalar"3. Já a empresa Starsec, disponibiliza o curso "Especialização em Segurança de Clínicas e Hospitais”. O site desta não continha dados sobre o curso. A empresa Escola Grande Rio apresenta o curso Agente de Segurança Hospitalar, com carga horária de dez horas. Segundo o site:

O curso tem por objetivo apresentar ao público alvo o perfil ideal de um Agente de Segurança Hospitalar (ASH) abordando questões comportamentais em unidades de saúde bem como a tomada de decisões em situações atípicas. Ao término do curso, o aluno estará tecnicamente capacitado a entender qual o seu papel no aspecto do atendimento diferenciado, da segurança do empreendimento e suas implicações ${ }^{4}$.

A maioria das empresas de formação de vigilantes não oferece capacitação na área de vigilância em hospitais ou em outras unidades de saúde. Diante da aparente indisponibilidade de informação formal acerca do trabalho dos vigilantes em unidades de saúde, consideramos fundamental verificar as orientações fornecidas aos vigilantes inseridos em unidades de saúde.

\section{Narrativas dos vigilantes}

A pesquisa contou com entrevistas com onze vigilantes, sete homens e cinco mulheres, de cinco instituições públicas de saúde do município do Rio de Janeiro, após aprovação do projeto no Comitê de Ética em Pesquisa, em junho de $2016^{5}$. Os sujeitos foram selecionados a partir do contato com alguns vigilantes, que indicaram outros sujeitos, método denominado "bola de neve" (NOY, 2008; HANDCOCK; GILE, 2011; VINUTO, 2014). A pesquisa teve início com as entrevistas de profissionais previamente identificados e com disponibilidade para participar, que recomendaram novos sujeitos. As entrevistas se basearam em roteiro semiestruturado, com perguntas sobre dados sociodemográficos, informações acerca da unidade de saúde de atuação do profissional, indagações sobre sua trajetória profissional e acerca da percepção do trabalho nesta unidade de saúde.

A idade dos entrevistados variou entre 43 e 62 anos, com média de 51 anos. Sete dos entrevistados declararam-se pardos, dois, pretos e dois, brancos. Nove entrevistados completaram o Ensino Médio e dois, o Ensino Fundamental. Oito consideram que sua profissão é "vigilante", ou vigilante e outra profissão, enquanto três referiram outras denominações. Como ocupação, dois responderam assistente administrativo posição assumida após promoção no trabalho como vigilantes - e nove declararam vigilante. Destes nove, dois também apresentaram outra ocupação em paralelo. Observamos que os profissionais que indicavam outros para entrevistas davam prioridade aos que possuíam maior tempo de trabalho na vigilância na área da saúde. Argumentavam que estes teriam mais experiência, razão pela qual entendiam as questões pertinentes ao campo de trabalho. O tempo médio de trabalho dos vigilantes entrevistados na área da saúde é de 15 anos e, na mesma instituição, de 13 anos.

Os serviços de saúde em que esses profissionais

3 http://www.grupocactus.com.br/seguranca-hospitalar/.

$4 \mathrm{http}: / /$ www.escolagranderio.com.br/ag-de-seguranca-hospitalar.

5 Projeto submetido ao CEP IESC/UFRJ; número do parecer de aprovação 1570.211. 
exercem suas atividades incluem: um hospital psiquiátrico, uma Clínica da Família, uma policlínica e dois hospitais terciários. A população alvo destes serviços abarca todas as faixas etárias e níveis de complexidade, inclusive serviços de emergência, pacientes em acompanhamento de condições crônicas de saúde, internação hospitalar e atendimento ambulatorial. Alguns profissionais entrevistados possuíam experiência de trabalho em mais de uma instituição de saúde, e compartilharam suas experiências de trabalho em até três instituições distintas. Nenhum entrevistado relatou experiência em instituições privadas de saúde.

Os vigilantes iniciaram sua vida laboral entre nove e quatorze anos de idade. A partir de então trabalharam em diversos locais, antes de ingressar na área da segurança. Após iniciado o percurso na segurança, muitos mantiveram outras atividades em paralelo para complementação de renda, como costura, bombeiro civil e estética. Apenas um entrevistado referiu encantamento e atração pela profissão, razão que o motivou a buscar a especialidade. Outro entrevistado indicou seu interesse devido à proximidade e semelhança com as forças armadas. Os outros afirmaram o interesse no ramo por ser, à ocasião, uma oportunidade de contar com melhores salários e condições laborais estáveis. Oito profissionais entrevistados afirmaram gostar do trabalho e desejam seguir com a mesma atividade. Três entrevistados indicaram gostar do trabalho, mas contam com outras pretensões profissionais.

Apenas uma entrevistada não frequentou o curso de formação requerido para exercer a função de vigilante. Contudo, atua como vigilante em uma Clínica da Família, tendo sido oficialmente contratada como "Auxiliar de Portaria". Segundo esta profissional, o mesmo ocorre em todas as Clínicas da Família. Devido à proximidade dessas unidades com áreas dominadas por grupos armados, a profissional avalia que o fato de não possuir curso de formação consiste em proteção a retaliações do grupo que domina o tráfico de drogas no local. Ela afirma que este é o motivo para não ter "tirado a ata" (feito o curso de formação), apesar da oportunidade oferecida.
Dois entrevistados iniciaram a carreira profissional como vigilantes e posteriormente foram convidados a integrar o quadro da instituição de saúde, de forma permanente, como "administrativos". Destes, um tornouse supervisor dos vigilantes por um período e posteriormente assumiu um posto de confiança na instituição. Ambos atuam como chefia informal dos vigilantes.

Apenas um entrevistado iniciou o trabalho na vigilância há 3 anos. Os outros vigilantes atuaram na área entre 16 e 30 anos. Seu trabalho na saúde contou com uma duração de pelo menos oito anos, e o trabalho na unidade de saúde atual por pelo menos sete anos. Apenas dois profissionais trabalharam desde o início na mesma instituição, mas já cobriram a falta de colegas em outras instituições por períodos limitados. A maioria dos entrevistados relatou experiência em diversos postos de trabalho, tanto fora quanto na área da saúde.

$\mathrm{O}$ fato de muitos vigilantes entrevistados contarem com experiência em mais de uma instituição possibilitou entrevistas ricas em dados e relatos acerca de diferentes unidades de trabalho. Como exemplo, vigilantes empregados, à ocasião, em unidades exclusivamente dedicadas aos portadores de uma doença específica e sem atendimento de emergência, relataram também suas experiências passadas em hospitais com setor de emergência aberta ao público e com atendimento a diferentes patologias. Outro exemplo é o fato de que, entre os entrevistados, apenas um vigilante estava atuando em hospital psiquiátrico no momento da entrevista, mas outro entrevistado descreveu suas experiências passadas em serviço psiquiátrico.

As entrevistas evidenciaram dois temas principais: a formação e o treinamento dos vigilantes, seus encontros/desencontros, adequação/inadequação ao trabalho; e a relação desses profissionais com as normas formais e informais da categoria. As falas apontam para a diferença entre o trabalho da "vigilância patrimonial", vinculado e submetido às normas da profissão; e o que concerne ao que denominamos aqui de "trabalho sem nome", realizado na área 
de saúde, com seus dilemas e "jeitinhos".

As falas que destacam o trabalho do vigilante "patrimonial" afirmam que o trabalho dos profissionais é cuidar do patrimônio da unidade: equipamentos, salas, controle de acesso. De acordo com as entrevistas, o dia a dia do trabalho do vigilante patrimonial varia de acordo com a instituição, mas de forma geral envolve: rondas ao longo do dia, passagem de plantão no início e no final do turno, controle de acesso à instituição e à entrada de setores específicos, contato com a polícia em casos de furto ou agressão dentro da unidade de saúde.

Além das atividades apresentadas enquanto referentes à "vigilância patrimonial" propriamente dita, nas entrevistas foram trazidas diversas atuações dos vigilantes que se encontram fora do escopo da legislação e do treinamento recebido por esses profissionais. Tais atividades foram evidenciadas em todas as entrevistas, envolvendo desde ações simples até atos com maior relevância, como a triagem informal realizada pelos vigilantes ou o uso de força na contenção de pacientes ou familiares. A atividade ganha novos traços e formas a partir das interações particulares de cada unidade de saúde, e parece não ter um nome exato. "Vamo botar aí, de 100\%, ele (o vigilante) faz 10\% do que é da função dele. Os $90 \%$ é da função de outro, do enfermeiro, de maqueiro...." (Entrevistado 1).

Como afirma um dos sujeitos, o "primeiro bom dia" dos pacientes é dado em geral pelos profissionais da vigilância, a quem os usuários do serviço irão dirigir muitas questões e dúvidas. Além disso, estando presentes no acesso ao hospital, são eles também os primeiros a encontrar pacientes que se encontram em situações de saúde agudas e graves ou potencialmente graves, muitas vezes sem a presença de um profissional de saúde treinado que possa fazer os serviços de avaliação de risco ou prestar os primeiros cuidados. Na ausência do maqueiro, os vigilantes que trabalham no portão do hospital por vezes se fazem de maqueiros, carregam pacientes no colo, levam cadeiras de roda. Por serem os primeiros abordados na chegada ao hospital, são em geral os primeiros a correr em auxílio de pacientes e familiares. Diversos vigilantes contam situações em que condições clínicas motivaram a quebra das regras. Os relatos de triagem informal por parte dos profissionais são comuns nas entrevistas. Também entre as atividades descritas pelos vigilantes nas entrevistas está o uso de força na contenção de pacientes e, até, de familiares, em situações nas quais a conversa e tentativas de convencimento não foram o suficiente para fazer as pessoas acederem às normas institucionais.

Apesar de apenas um entrevistado utilizar o termo "desvio de função", a maioria dos entrevistados referiu atividades não normatizadas como "não-patrimoniais" ou tarefas para além de suas atividades de "vigilância patrimonial" - as atividades "fora da norma". Estas consistem em uma transformação da norma, que responde a problemas encontrados no cotidiano institucional, criando um "jeitinho". O “jeitinho" é uma categoria situada "entre o legal e o ilegal, entre o prescrito e o realizado" (Barbosa, 1988, p. 51).

O vigilante se apresenta como parte do “dilema brasileiro" (DaMatta 1997), na oscilação entre o indivíduo das leis universais e a pessoa das relações sociais. Por vezes, são as normas da empresa que devem ser obedecidas, em outras, é a situação pessoal que determina as regras. Os vigilantes oscilam entre a autoridade impessoal das normas e do aprendizado formal recebido e as relações pessoais, estabelecidas no cotidiano.

\section{A formação do vigilante patrimonial na saúde}

"Porque você não aprende isso lá (no curso). Você aprende no teu cotidiano, no teu dia a dia” (Entrevistado 9). A formação do vigilante patrimonial começa com o Curso de Formação de Vigilante, tem continuidade nos cursos de reciclagem obrigatórios, realizados a cada dois anos. Oficialmente, esses são os dois canais de formação e aprendizado do vigilante patrimonial. Entretanto, o curso inicial e os de reciclagem possuem pouca ou nenhuma informação sobre o trabalho de vigilância em unidades de saúde. O aprendizado associado à atuação na área da 
saúde e na especificidade de suas instituições se dá a partir da entrada no campo de atuação, na prática dos serviços de saúde, e é transmitido de um profissional a outro, conforme explicitado na seguinte entrevista:

Não tem nada a ver com o que você aprende no curso de reciclagem... Você aprende a lidar com patrimônio, você aprende combate a incêndio. São revisões do curso que você fez de vigilante. Você aprende combate a incêndio, primeiros socorros. Agora, essa parte de ir trabalhar no hospital, aprender a lidar com os pacientes, lidar com os funcionários é difícil. Porque você não aprende isso lá. Você aprende no teu cotidiano, no teu dia a dia (Entrevistado 9).

Segundo os entrevistados, as empresas são contratadas pelo governo após licitação. A partir de então, enviam os vigilantes de seu quadro de pessoal para diferentes postos de trabalho, inclusive unidades de saúde. Os vigilantes são encaminhados pela empresa com o curso básico de formação e os de reciclagem. Contudo, somente ao chegar à unidade eles recebem informações sobre a natureza do trabalho naquele local. Em geral, esse aprendizado ocorre de maneira informal, seja por parte do supervisor ou do funcionário da administração que tem contato próximo e direto com os vigilantes, ou pelo contato e observação de colegas mais antigos ou, ainda, por meio da orientação da equipe de saúde daquela unidade. Nas palavras de dois entrevistados:

Porque a formação, ela é muito básica e segue uma linha geral. Por exemplo, "Isso aqui você tem que fazer assim, assim, assado". É só quando você vai trabalhar em um setor, o que acontece, cada setor tem a sua metodologia de trabalho. O hospital, você tem um jeito de trabalhar, numa indústria, você tem outro meio de trabalhar. De uma indústria pra um hospital existe essa diferença. A formação, ela não te dá essa visão. Essa visão você vai obter na medida em que você vai trabalhando, mudando de postos, aí você vai tendo essa visão (E5).
Já faz parte, quando vai daqui pra uma unidade, cada unidade é um estilo diferente de trabalhar. Onde você chega, no posto, aí que vão falar como é que é o trabalho no posto em si. Na unidade é que vão dizer pra você como é o procedimento do trabalho (E3).

Nos cursos de formação são fornecidas informações básicas referentes ao trabalho em qualquer unidade e posição, como a legislação da área, controle de incêndio, primeiros socorros, uso de armamento e defesa pessoal. Na chegada ao posto, o vigilante é orientado acerca da posição e do papel específico a ser desempenhado, como, por exemplo, o controle de acesso do portão principal ou de determinada área da unidade. Os vigilantes aprendem não apenas com o que é falado, mas também, observando como outros profissionais lidam com situações desafiadoras, e ainda, questionando a forma de realizar alguma intervenção. A importância da observação de colegas mais experientes no posto e o lugar do supervisor neste aprendizado informal são explicitados, de modo a possibilitar que os vigilantes apreendam o quanto cada situação ou comportamento é ou não esperado, se é classificado ou não como adequado ou inadequado, na abordagem e no contato com o público da unidade de saúde. O papel dos profissionais da saúde na formação dos vigilantes é abordado nas entrevistas, como nos trechos a seguir:

Uns amigos meus de profissão, vigilantes, que me explicaram: "É assim, assim, assim”. Assim quando começou era pra ficar no setor, não deixar a pessoa mexer, danificar... Aí foram os próprios colegas de cada unidade que foram passando como é que era através da administração, que ela que explicava como é que ela queria que os vigilantes fizessem. Aí a parte administrativa: "Fica aí que eu quero que você fique de olho em tal lugar assim, assim. Fica ali, que ali é tal coisa assim”. A administração é que faz isso (E3).

Olha, nós vigilantes temos um curso de formação. Então nesse curso nós aprendemos 
o curso de tiro, defesa pessoal, parte da saúde também, primeiros socorros, combate a incêndio, direito, várias coisas. Aí na área da saúde, depois que eu vim pra cá eu passei a conhecer o sistema de trabalho. O sistema de trabalho é assim, como você se comporta, como é, como não é. Algumas coisas assim. Não é aquele curso longo especifico, mas nos dá o básico e o restante nós vamos aprender no dia a dia, como se comportar em certas situações, os cuidados que você tem que ter, lavação de mão, aquela coisa toda... Nesse ponto, não tivemos um curso, as pessoas vão ensinando pra gente. Até médico mesmo: "Rapaz, ó, quando você entrar lá dentro, lava sua mão. Quando for fazer a ronda e tal" (E5).

Para além da especificidade do trabalho em instituição de saúde há, também, a especificidade do trabalho em determinada unidade, em certo posto de trabalho. As empresas não fornecem informações sobreas diferenças do trabalho nesses postos. Segundo alguns vigilantes entrevistados, as empresas não sabem, de fato, o que eles fazem nas unidades de saúde. As características do trabalho e as tarefas específicas são acordadas internamente e seguem as características de cada unidade:

No posto que você for é que vão indicar qual é o serviço, porque a firma mesmo não sabe. A firma mesmo não sabe que a gente faz um monte de coisa (E3).

Alguns vigilantes entrevistados entendem que o curso de formação e o aprendizado informal no cotidiano das unidades é o suficiente para suprir o profissional da segurança com os dados necessários para executar seu trabalho. Alguns profissionais aventam a hipótese de que, caso fossem oferecidas mais informações, poderia acarretar um aumento do que é classificado como desvios da função na vigilância.

Não... Esse aprendizado já tá de bom tamanho. Não precisa de mais não... Sabemos fazer quase tudo aqui. Vai acabar a gente fugindo, a gente fazendo outra função só, e a nossa mesmo a gente não vai fazer. Acho que tá bom, cada um tem que estar dentro da sua função. Ajuda é muito bom. A gente não pode também fugir da função nossa (E9).

Para alguns vigilantes, a alocação em qualquer tipo de estabelecimento inviabiliza uma oferta de curso específico sobre atuação na área da saúde:

Porque todo mundo quando vai trabalhar de vigilante, tem que ter esse curso. Aí quando vai botar o currículo, aí depende da firma que você conseguir, aí (a firma) vai botar num posto de saúde, vai botar numa escola. Cada firma trabalha num local. Às vezes é num depósito. Cada firma tem um contrato num local. Pode ser num posto de gasolina, num posto de saúde, numa biblioteca, pode ser em uma agência de carro. É assim, aí não tem aquele curso especifico. Quando você vai para aquele local, lá que você tem que trabalhar no ritmo que você tá naquele local de trabalho. Por isso que não pode ter curso antes, pra você chegar e trabalhar. Depende do local que você vai conseguir de contrato da firma (E3).

Embora alguns entrevistados tenham estas opiniões, outros vigilantes criticam a sua formação, que consideram falha e incompleta. Muitos entrevistados responsabilizam a formação pela atuação inadequada de certos profissionais. Esta postura é associada ao uso da violência no trabalho. Segundo um entrevistado, para atuar em instituições de saúde de forma adequada seria necessário transmitir informações que não são oferecidas aos profissionais. Ele avalia a importância de mudanças na formação dos vigilantes que são designados para atuar em unidades de saúde.

Como você vê. Eu sou vigilante, como eu muitos colegas. Então, você tem uma formação como eu tive e de vários outros lugares, várias outras formas de trabalhar. E é assim, basicamente é bem diferente de uma área de saúde de um hospital tipo esse, que você tem que ter assim, você tem que ter noção do que você está fazendo. E nem sempre tem. Nem sempre você tem um profissional preparado. Não se prepara profissional de segurança pra essa 
área. Você não tem. Você tem pessoas que, quando querem se enquadram, tentam, como eu, eu sempre tentei me enquadrar de forma que eu não me prejudique e não prejudique terceiros (E9).

Em alguns relatos, há propostas de melhora na formação dos vigilantes, para capacitálos a atuarem em unidades de saúde, para um aprendizado de certas tarefas, como carregar pacientes ou identificar situações e casos de emergência.

Então, os cursos são muito básicos. Há uma cobrança considerada às vezes até um pouco exagerada, no trabalho do vigilante, porém, um detalhe, muitas das vezes o erro não está nele, mas no tipo de formação que ele teve. Se ele não tiver uma empatia pra tentar entender as pessoas, e procurar conversar com as pessoas como tem que ser, ou seja, separando cada assunto de acordo com a reação da pessoa, ele vai se perder, fica perdido no espaço. Aí o que acontece, chega uma hora que ele mesmo chega "ah, o melhor mesmo é dar uma pranchada logo". Aí é quando acontecem determinadas violências (E5).

Um entrevistado apresenta uma crítica ao que considera ser uma formação inadequada aos profissionais, e refere que tem abordado essa falha nos cursos de formação em que participa. Para ele, o produto das formações seria um vigilante mecânico, incapaz de se adequar ao seu ambiente de trabalho, ou fazer algo que ultrapasse o nível de formação recebido:

Eu já várias vezes fazendo a minha reciclagem, porque a gente tem que se reciclar a cada dois anos, na reciclagem eu tenho debatido muito isso nos cursos, que não há um aprimoramento. As reciclagens são muito básicas e praticamente se remetem ao que foi aprendido nas formações. Então quer dizer, o vigilante entra lá de uma forma e sai do mesmo jeito, não há uma mudança. Muito mal se há uma determinação em lei pra alguma coisa “Ó, vocês tomem cuidado, a lei assim e assim". Mas fora isso, nada mais. Nada de tornar o vigilante um pouco mais humano, ele continua sendo aquele tipo daquela máquina. "Fica aí. Você tá aqui estático, você tá aqui só porque a companhia de seguro exige”. Então, muitas vezes eles agem dessa forma, chega e fica estático (E5).

A limitação das informações recebidas nos cursos contrapõe-se aos desafios na rotina laboral em unidades de saúde. Por ocuparem uma posição de exposição e contato com os usuários dos serviços de saúde, tanto com pacientes quanto com seus familiares, por vezes são expostos a situações que demandam um posicionamento imediato. No entanto, a formação oficial não forneceu qualquer orientação para o enfrentamento deste tipo de evento. Assim, sua atitude segue o recebido no processo de aprendizado informal e, também, baseia-se em seus valores pessoais:

E nisso aí entra o trabalho do vigilante, em ele também, não é bem a função dele, mas é uma interatividade tão grande que o vigilante já chega já entrando nessa questão. Não seria o trabalho dele, porém um detalhe, ele chega e fica de frente com a situação, ele não tem como evitar. Então ele tem que ser preparado pra essa situação. $O$ vigilante tem que ser uma pessoa calma, tem que ser uma pessoa tranquila, tem que saber conversar com as pessoas, entendeu, ele tem que ser preparado. Os cursos que, como falei, os cursos eles dão informação em linha geral, eles não dão um preparo para você chegar e, "ah, olha", "não senhor, fica calmo". Nada disso. Simplesmente, "o teu trabalho é esse, e você não se mete aqui, e não se mete ali. É isso aqui, tu foca nisso aqui. Você tem que chegar e não deixar a pessoa passar e acabou, se tiver que bater, bata" \{voz autoritária\}. Essa é a linha geral dos cursos pra ensinar o vigilante (E5).

$\mathrm{Na}$ atuação em unidade de saúde, o vigilante cria parâmetros e regras próprias, o que pode ser ilustrado pela fala do entrevistado 9 .

Se você pegar um paciente que tem problema nas articulações, você sabe? Não. Sua função ali é chegar e ajudar a pessoa a botar no carro. Por isso que eu falo, pede ao acompanhante pra pegar 
o paciente pra botar no carro. Você só vai fazer o acompanhamento. "A senhora quer que eu ajude? Eu posso ajudar? Se eu pegar aqui na senhora com certa força, vai te machucar?”. Isso eu não vejo. Falta orientação. Orientação voltada pra área de saúde. Pra área administrativa não. Você tem seguranças dentro dos hospitais? Tem. Mas tudo voltado pra área administrativa. Relativo à saúde não temos. Porque eu não tenho uma orientação técnica sobre como segurar. Aí eu percebo que você vai cair. Qual o meu intuito? Te segurar. Se eu sei que você pode ter problema nos membros superiores, eu vou automaticamente tentar te pegar na cintura, evitar essa área. Ou simplesmente vou fingir que não vi, tu vai cair no chão (E9).

Esta e outras falas apontam a percepção dos vigilantes de que seu conhecimento em relação à saúde é limitado. Os relatos indicam três possibilidades no lidar com a questão:

1. Um esforço individual do profissional para preencher as lacunas em seu processo de aprendizado, envolvendo observação e busca por cursos "extras":

Eu fiz cursos de supervisão. O nome é só um título. Nesses cursos a gente aprende a não só ter empatia, mas saber o que ela significa. Foi um dos cursos que fiz. Outros cursos, você saber como lidar com o ser humano. Você ter a calma acima de tudo, procurar conversar com as pessoas, procurar entender - tá aí a empatia na situação - o problema que ela está passando e você se colocar no lugar dela pra você ter como orientar ela naquilo que ela tá tentando obter. Ela veio pra obter alguma coisa. Que seja uma visita, que seja um atendimento médico. Esses cursos ajudam muito a gente, tem vários locais que dão esses cursos. Então quem se interessa em fazer, faz. A maioria não se interessa, a maioria maciça da vigilância não tem curso quase nenhum, a não ser aqueles básicos. São poucos que procuram se interessar em fazer os cursos de especialização. Quer dizer, eu considero especialização. Você fazendo um curso desses e você aprendendo mesmo o que é ensinado, você volta diferente para o posto. Você volta com uma nova visão, um novo jeito de comportamento (E4).
2. A instituição forneceria ensino aos vigilantes:

Olha, o treinamento que eu acho que deveria ter seria o seguinte: pegaria um funcionário especifico, um enfermeiro. Esse enfermeiro ia instruir o segurança. Tanto enfermeiro quanto médico que já acompanha há bastante tempo a área de psiquiatria, e o psicólogo acompanhando também, pra fazer uma avaliação de quem está entrando, e se a pessoa vai gostar do que vai encontrar ou não. Fazendo uma avaliação em cima do que vai ser passado pro segurança (E9).

3. O ensino de forma sistematizada pelo governo, por intermédio do Ministério da Saúde:

Nós não temos isso. Mas eu acho que deveria vir de dentro. Você está fazendo a pesquisa pra colocar “Qual a função desse individuo aqui dentro?”. Ou seria "Qual a função daqui de dentro com esse indivíduo"? Eu acho que tudo bem, vocês estão fazendo a pesquisa, mas por mim eu começaria de dentro pra fora. Ou seja, do Ministério da Saúde para o vigilante. Tudo bem, quer ter uma noção. Mas pergunta "O que você espera que o rapaz faça? Ele só vai atuar numa área?” (E9).

As falas dos entrevistados E9 e E10 se destacam, pois apontam a importância de uma capacitação no sentido de promover interação com as pessoas, um desafio presente em muitos relatos. Para E10, o desgaste dos vigilantes, produzido pelo contato constante com a dor, sofrimento e, até, com a agressividade do público deveriam ser aplacados por meio de intervenção de profissionais da saúde mental:

Mas é conflitante no sentido de que você, você não vem com uma cartilha, você não vem com um manual de instrução. Você tem que aprender a trabalhar e nem sempre está apto a fazer isso, porque não só nessa área de saúde, mas segurança em geral, sempre foi descaracterizado. Quem está trabalhando na área de saúde não tem acompanhamento psicológico, que acho que deveria ter. Uma avaliação fora do patrão e da 
empresa contratante, um profissional dentro da área de saúde pra avaliar a conduta, o modo daquela pessoa. Porque você trabalhar com pessoas que são portadoras de câncer, você tem que avaliar muito o jeito de você lidar com a pessoa, de conversar com a pessoa. Ao mesmo tempo em que você tem que se envolver, você tem que se afastar. Você se envolve no intuito de ajudar, e se afasta no intuito de não ser pego se envolvendo demais. Aí você vê profissionais mal treinados em instituições de saúde que brigam, que literalmente saem na porrada com as pessoas. Você não tem um posicionamento tipo assim: "gente, esse hospital ou essa unidade hospitalar, não é igual a tal, ou a outra tal. Ou mesmo o que tá acontecendo com a unidade tal não acontece aqui". Como segurança, você trabalha com a pessoa, com o ser humano. Na minha área de segurança, o que sempre foi difícil é a pessoa, é o ser humano em si (E10).

Essas falas e outras evidenciam a dificuldade no trabalho do vigilante que atua em unidade de saúde, no contato com pessoas doentes. Diante de situações que envolvem sofrimento, emergem emoções e afetos. O relato de E10 explicita sua demanda por atenção aos aspectos sociais e emocionais no trabalho, não apenas enquanto cuidado à saúde dos profissionais envolvidos, mas enquanto possibilidade de capacitação para lidar com os aspectos "menos técnicos" de sua atuação, para prevenção da violência.

A interação com pessoas, bem como as demandas por atividades distintas ao que foi ensinado nos cursos de formação constituem relevantes desafios no cotidiano em unidades de saúde. O trabalho efetivamente realizado pelos vigilantes não somente é muito diferente do que é transmitido nos cursos, como também se distancia das normas da categoria profissional, como revelam as entrevistas.

\section{Entre a norma e o "jeitinho"}

A análise dos dados coletados na pesquisa documental e nas entrevistas com vigilantes revelou importante diferença entre o que é normatizado pela legislação da área de atuação, e as atividades empreendidas pelos vigilantes em seu cotidiano em unidades de saúde.

A pesquisa documental evidenciou que os cursos de formação para vigilantes e os de reciclagem, realizados a cada dois anos, fornecem escassa informação sobre o trabalho na área da saúde. De fato, a Portaria no 3.233/12, que regulamenta os cursos na área, não inclui a "vigilância hospitalar" no rol dos cursos de formação, extensão ou reciclagem. Dentre as empresas de formação sediadas no município do Rio de Janeiro encontradas em levantamento na internet, apenas três oferecem cursos de especialização em vigilância hospitalar, com carga horária máxima de dez horas de aula, que não são obrigatórios para atuação laboral na área. Em paralelo, nenhum dos onze vigilantes entrevistados relatou ter frequentado este tipo de curso. Suas falas apontaram para uma formação e treinamentos informais, no trabalho em instituições de saúde.

A “especialização" efetivamente empreendida por estes profissionais ocorre em seu cotidiano, a partir de orientações e exemplos dos distintos atores sociais presentes na cena hospitalar: outros vigilantes, supervisores, médicos, enfermeiros e técnicos de enfermagem, entre outros. Esse aprendizado informal preenche algumas lacunas, com informações que ultrapassam os dados técnicos, uma vez que ensinam o como-fazer e como-se-portar no cenário institucional, explicitando os limites do que é ou não esperado naquele ambiente. A equipe de saúde veicula determinadas informações, como a importância de lavar as mãos ao entrar e permanecer em locais de atendimento, a adequação ou não da permanência de um visitante ou familiar, em relação ao estado de saúde de um paciente. A partir da observação, aprendem os sinais de agravamento de um quadro clínico e as características de situações que demandam atendimento urgente.

Alguns vigilantes afirmaram desejar aprofundar seus conhecimentos, por orientação sistemática, envolvendo sinais clínicos de urgência, orientação acerca da abordagem de pacientes e familiares, no que concerne ao 
sofrimento decorrente do contato com a doença e a morte. De acordo com um entrevistado, "a instituição deveria se preocupar com o que está fazendo pelos vigilantes, mais do que se preocupar com o que os vigilantes fazem pela instituição". Ele sugere que o Ministério da Saúde se envolva nessa questão, oferecendo treinamento formal e atendimento para os vigilantes que necessitarem, "para amenizar os efeitos maléficos da exposição do trabalhador ao sofrimento e à morte", além da possibilidade de contribuir para melhoria da atuação desses profissionais.

Assim, as dores apontadas pelos vigilantes se aproximam das percebidas por profissionais de saúde, para os quais o contato cotidiano com a "dor e morte como ofício" demanda suporte e tratamento, em muitos casos (PITTA, 1990). As falas dos vigilantes evidenciam um processo de sensibilização, no trabalho na área da saúde, por vezes, com posterior dessensibilização gradual. Tal processo é análogo ao descrito acerca de profissionais da saúde, que aparentemente se "acostumam" ao contato diário com o sofrimento de pacientes e familiares (HERZLICH, 1993; MENEZES, 2006).

As falas apontam a restrita proteção desses profissionais, quando efetuam atividades não previstas, como contato com pacientes com risco de contaminação, cuja proteção por vezes não é oferecida aos vigilantes, pelo pressuposto de que eles não integram a equipe de saúde. A preocupação dos vigilantes com a possibilidade de contágio pelo vírus HIV, bem como por tuberculose ou por vírus ou bactérias transmitidos por via aérea não consiste em objeto de atenção ou de cuidados dirigidos a estes profissionais, por parte da unidade de saúde, empresa ou de qualquer outra instância. A saúde dos profissionais também está situada fora da norma.

As consequências indesejadas da realização de tarefas que abrangem desde a probabilidade de ferir um paciente - no caso de contenção de doente descontrolado ou ao carregar um enfermo debilitado - contaminação, até o risco de sofrer ameaças ou dano físico - pela agressividade de paciente em tratamento psiquiátrico ou de usuários e familiares descontentes com falhas na unidade de saúde. Apesar dos diferentes riscos envolvidos no cumprimento de seu trabalho, em poucas falas os vigilantes entrevistados referiram reconhecimento, da parte das unidades de saúde em que atuavam, das atividades por eles empreendidas, ou foi oferecido algum treinamento específico. Essa situação se distingue do ocorrido na instituição pesquisada por Calegari e Lima (2008), na qual os vigilantes foram incluídos em uma "Comissão Permanente de Humanização" e receberam "treinamento de colaboradores", a partir do entendimento da complexidade das tarefas por eles desenvolvidas.

\section{Considerações finais}

Este artigo abordou o trabalho realizado por vigilantes em unidades de saúde, no que tange à formação oferecida para tal atividade. Apontou a multiplicidade de tarefas realizadas e a escassez de informação recebida na formação desses profissionais, bem como a importância de uma formação informal, nas unidades em que atuam. A pesquisa evidenciou a importância da disponibilização de cursos que fundamentem o trabalho dos vigilantes em instituições de saúde, indicando os limites de sua atuação nos níveis institucional e administrativo e, sobretudo, no que tange às interações com usuários dos serviços de saúde. As narrativas dos entrevistados apontaram a carência de formação e treinamento específicos abordando as tarefas e os desafios enfrentados pelos profissionais, em sua atuação na área de saúde, destacando suas peculiaridades e dinâmica próprias, além de prepará-los para o contato com a doença, o sofrimento e a morte.

As entrevistas indicaram uma demanda por instrução, para proteger os vigilantes dos possíveis riscos no trabalho em instituição de saúde, bem como por oferta de suporte para o sofrimento psíquico proveniente do contato com pacientes e familiares, com o quadro de carência de recursos e a situação precária de muitas unidades de saúde. Por fim, concluímos que, enquanto o trabalho de vigilantes e de outras categorias profissionais presentes em unidades de saúde, 
como na limpeza e o pessoal administrativo, não contar com um reconhecimento de seu lugar específico e peculiar, pela proximidade com o campo da saúde, não será possível oferecer a esses profissionais uma atenção e formação adequadas ao trabalho que realizam. Neste sentido, não é possível abordar estes profissionais em ações de "cuidado para quem cuida", uma vez que não são considerados como integrantes da equipe de saúde que efetua tarefas de cuidado.

Não se trata aqui de criticar ou apontar falhas dos vigilantes nem de enaltecer seu trabalho, mas de entender sua atuação, no âmbito do funcionamento das instituições de saúde. Este artigo não esgota as possibilidades de abordagem e de interpretação acerca do trabalho de vigilantes em unidades de saúde. Nesta direção, indicamos a relevância de estudos que contemplem as interações entre estes, os pacientes e seus familiares, e com membros da equipe de saúde, além do impacto de suas ações sobre o funcionamento institucional.

\section{Referências bibliográficas}

ABCFAV. Manual do Vigilante - Associação Brasileira dos Cursos de Formação e Aperfeiçoamento dos Vigilantes. - Volume 1, Brasília/DF, 2007. Disponível em http://www. dpf.gov.br/

BARBOSA, L. O jeitinho brasileiro. Rio de Janeiro: Campus, 2005.

BARROS, M. E. B. et al. Narrativas sobre uma intervenção numa Unidade Básica de Saúde da Grande Vitória/ES, Mnemosine, v. 9, n. 1, p. 192204, 2013.

BRASIL. Ministério da Justiça. Departamento de Polícia Federal. Portaria no 3.233/2012-DG/ DPF, de 10 de dezembro de 2012. Disponível em: <BRASIL. http://www.pf.gov.br/servicos/ seguranca-privada/legislacao-normas-eorientacoes/portarias/Portaria\%20n3233.12. DG-DPF.pdf >. Acesso em: 12 nov. 2015.
BRASIL. Ministério do Trabalho e Emprego. Classificação Brasileira de Ocupações - CBO 2002: códigos, títulos e descrições. Brasília, DF, 2002. Livro 1. Disponível em: <http://www.sine. rn.gov.br/cbo/CBO2002Liv1.pdf>. Acesso em: 12 nov. 2015.

BRASIL. Presidência da República. Casa Civil. Lei $\mathrm{n}^{\circ} 7.102$, de 20 de junho de 1983. Disponível em: < http://www.planalto.gov.br/CCIVIL_03/ leis/L7102.htm>. Acesso em: 16 nov. 2015.

FARIA, H. X. No fio da navalha: o processo de trabalho de uma unidade de saúde da família de Vila Velha-ES. 2010. 136 f. Dissertação (Mestrado - Psicologia institucional). Universidade Federal do Espírito Santo. Centro de Ciências Humanas e Sociais. Vitória, 2010.

CALEGARI, Rita de Cassia; LIMA, Abgair Xavier. Ações de humanização frente à morte no ambiente hospitalar. Bioéticos: Centro Universitário São Camilo, v. 2, n.1, p.115-119, 2008 .

COELHO, M. O.; JORGE, M. S. B. Tecnologia das relações como dispositivo do atendimento humanizado na atenção básica à saúde na perspectiva do acesso, do acolhimento e do vínculo. Ciência \& Saúde Coletiva, v. 14, supl. 1, p. 15231531, 2009.

DAMATTA, R. "Você sabe com quem está falando?”. In: DAMATTA, Roberto. Carnavais, malandros e heróis. Rio de Janeiro: Rocco, 1997.

GIGLIO-JACQUEMOT, Armelle. Urgências e emergências em saúde: perspectivas de profissionais e usuários. Rio de Janeiro: Fiocruz, 2005.

HANDCOCK, M. S.; GILE, K. J. Comment: on the concept of snowball sampling. Sociological Methodology, v.41, n.1, p.367-371, August 2011.

HERZLICH, Claudine. Os encargos da morte. Rio de Janeiro: IMS/UERJ, 1993. 
MENEZES, Rachel Aisengart. Difíceis decisões. Etnografia de um centro de tratamento intensivo. Rio de Janeiro: Fiocruz, 2006.

NOY, C. Sampling knowledge: the hermeceutics of snowball sampling in qualitative research. INt J Social Research Metodology, v.11, n.4, Oct., p. 327-344, 2008.

PITTA, Ana. Hospital: dor e morte como ofício. São Paulo: Hucitec, 1990.

QUEIROZ, Y. L.; FERREIRA, C. B.; SILVA, A. M. F. Práticas em um CAPS de Minas Gerais. Revista da SPAGESP, v. 14, n. 2, p. 126-137, 2013.

VINUTO, J. A amostragem em bola de neve na pesquisa qualitativa: um debate em aberto. Temáticas, Campinas, v.22, n. 44, p. 203-220, ago/dez 2014. 